\title{
Clinical Outcomes of Rectal Carcinoids: A Single-Institution Experience
}

\author{
Xiaoli Zheng ${ }^{1}$, Yufei $\mathrm{Lu}^{1}$, Siguo Cheng ${ }^{2}$, Chengliang Yang ${ }^{1}$, Hong $\mathrm{Ge}^{1}$ \\ ${ }^{1}$ Department of Radiation Oncology, Henan Cancer Hospital, the Affiliated Cancer Hospital of Zhengzhou \\ University, Zhengzhou 450003, Henan Province, China. \\ ${ }^{2}$ Henan Red Cross Blood Center, Zhengzhou 450001, Henan Province, China. \\ gehong66@gmail.com
}

\begin{abstract}
To report clinical outcomes of rectal carcinoids through investigating patients with rectal carcinoid. Between December 2011 and January 2003, 16 consecutive patients with biopsy-proven rectal carcinoid were enrolled at our institution, including ten males and six females, with a medial age of 49 years old (range 29 to 78 years). The median tumor size was $12.3 \mathrm{~mm}$, five lesions diameter were $\geq 20 \mathrm{~mm}$, eight lesions diameter were $\leq$ $10 \mathrm{~mm}$, three lesions diameter were $10 \mathrm{~mm}-20 \mathrm{~mm}$. All rectal lesions were located within $10 \mathrm{~cm}$ from the anal verge. 9 cases underwent transanal local excision; 3 cases had received anterior resection (Dixon); 2 cases underwent abdominaloperineal resection (APR); 2 cases underwent Endoscopic submucosal dissection (ESD).2 of patients received postoperative chemotherapy or radiation therapy. Calculation of the 5-year overall survival (OS), recurrence-free survival (RFS) and cancer specific survival (CSS) were performed by Kaplan-Meier methodology. All patients were followed up for a median of 45.4 months (Range: 6 to 161 months), no patient was lost to follow-up. The 5-year OS, RFS and CSS were $85.2 \%, 93.8 \%$ and $90.9 \%$ respectively. Rectal carcinoids had a favorable prognosis, an adequate resection play key role in management of rectal carcinoid tumors, the extent of the surgical resection depend on its size, its anticipated stage and the specific patient needs.
\end{abstract}

[Xiaoli Zheng, Yufei Lu, Siguo Cheng, Chengliang Yang, Hong Ge. Clinical Outcomes of Rectal Carcinoids: A Single-Institution Experience.Life Sci J 2012;9(4):1611-1614] (ISSN:1097-8135). http://www.lifesciencesite.com. 246

Key words: Clinical outcomes; Neuroendocrine tumors; Rectal carcinoids

\section{Introduction}

Carcinoid tumors are a group of neoplasms with neuroendocrine features, which originate from argyrophil cells in intestinal mucosal glands. Rectal carcinoids are relatively rare, but are on the rise as the degree of screening sigmoidoscopy and colonoscopy increases in the last few years, accounting for approximately $17 \% \sim 25 \%$ of all gastrointestinal tract carcinoids and $1.3 \%$ of all rectal tumors ${ }^{[1]}$. Rectal carcinoids are most often small and confined to the submucosa, they tend to show nonfunctioning and asymptomatic and are more likely to be found incidentally when compared with carcinoids at other sites. Generally, Rectal carcinoid tumors have been recongnized as having low malignant potential ${ }^{[2]}$. However, recent studies have shown that carcinoid tumors with metastasis are thought to be tumors with a malignant potential comparable to that of an adenocarcinoma ${ }^{[3]}$. Even there has been report of small-sized carcinoid tumors with considerable rate of lymph node metastasis ${ }^{[4]}$.In the recently revised the American Joint Council on Cancer (AJCC) cancer staging, carcinoid tumors are classified as a malignant tumor ${ }^{[5]}$. Surgical resection has been the standard treatment of patients with rectal carcinoids, but there are still some controversy. The purpose of this report was to demonstrate the treatment outcomes of patients with rectal carcinoids in our institution.

\section{Patients and Methords}

Between December 2011 and January 2003, 16 consecutive patients with biopsy-proven rectal carcinoid were enrolled at our institution. Tumors diameters at the time of diagnosis were measured from the colonoscopic examinations. The median tumor size was $12.3 \mathrm{~mm}$ (range, $3 \mathrm{~mm}$ to $23 \mathrm{~mm}$ ), five lesions diameter were $\geq 20 \mathrm{~mm}$, eight lesions diameter were $\leq$ $10 \mathrm{~mm}$, three lesions diameter were $10 \mathrm{~mm}-20 \mathrm{~mm}$. All rectal lesions were located within $10 \mathrm{~cm}$ from the anal verge, the median distance of rectal carcinoids from the anal verge was $5.9 \mathrm{~cm}$ (range, 2 to $10 \mathrm{~cm}$ ). All patients underwent chest, abdomen, pelvic computed tomography (CT) scans with intravenous contrast agent and colonoscopy examinations prior to surgery. Lymph nodal involvement was considered for a lymph node with a minimal diameter more than $5 \mathrm{~mm}$ on the preoperative CT sets, only one case was diagnosed lymph node metastasis at mesentery. All patients were clinically staged according to the AJCC Cancer Staging $7^{\text {th }}$ edition, revised in $2010^{[5]}$. The Ki-67 ratios of all patients were detected by immunohistochemical staining using formalin aceticacid-fixed, paraffin-embedded postoperative specimens tissue sections. In addition, one of the patients had an active double cancer in his left inferior lung, the lung lesion were pathologically proven as lung adenocarcinoma, 
No patient presented with the carcinoid syndrome. The clinical characteristic was shown in Tab. 1.

Surgery were performed in 16 patients, Among $11 \leq 20 \mathrm{~mm}$-diameter rectal lesions: 9 lesions were resected by transanal local excision, 2 lesions were removed by endoscopic submucosal dissection (ESD), while the one (patient 16) with an alive double cancer received prescription dose $60 \mathrm{~Gy}$ in 30 fractions to his lung lesion after ESD. 5 patients $\geq 20 \mathrm{~mm}$-diameter rectal tumors, 2 cases received Dixon, 2 cases underwent APR and 1 case underwent transanal local excision. Among the 16 patients, only 1 patient (patient 11) with narrow tumor-free (an inadequate resection) received postoperative radiation therapy with prescription dose of 50Gy in 25 fractions after local excision, 1 patient (patient 1) with positive lymph node (T2N1M0) received postoperative chemotherapy (oxaliplatin 200mg on Days1) every 3 weeks for two cycles. The remaining 14 patients did not receive any adjuvant therapy.

\section{Follow-up and Statistical Analysis}

Patients were usually followed up at 3 and 6 months after treatment and at one year intervals thereafter. The follow-up investigations were documented for each patient (e.g. physical examination, chest, abdomen and pelvic CT and colonoscopy examinations). The diagnosis of relapsing or metastatic disease was made in accordance with the results of biopsy findings or/and imaging examinations,

OS and CSS rates were calculated for the interval from the date of surgery until death because of any cause and rectal carcinoid, respectively. RFS was defined as the period from date of surgery to the date of first documented evidence of distal or local recurrent disease. Kaplan-Meier method were used estimate the OS, CSS and RFS. All statistical analyses were performed using SPSS 17.0 software (SPSS, Chicago, IL).

\section{Results}

16 rectal lesions were confirmed rectal carcinoid on the basis of the postoperative routine pathological examination, which led to visual description of $68.75 \%$ $(11 / 16)$ tumors invading submucosal, 6.25\% (1/16) invading mucosal, and $25 \%(4 / 16)$ invading muscular. Immunohistochemical staining: the Ki-67 labeling index of all lesions were below $4 \%$.

Until February 2012, all patients were followed for a median of 45.4 months, with a range of 6 to 161 months, no patient was lost to follow-up. There were 3 cases for following up full for 5 years. At time of follow-up, 14 patients were alive, 2 patients had died. A 29 -year -old male patient (patient 4) who underwent transanal local excision relapsed in 6 months and died in 18 months after initial treatment, because he refused to therapy again. And a 78 -year-old male patient (patient 16) with an active double cancer died from lung cancer progression in 9 months after ESD. No local recurrence or metastasis was found in the other 14 patients. The 5- year OS and CSS as well as RFS were $85.2 \%, 93.8 \%$ and $90.9 \%$ respectively (Fig. 1).

\section{Discussions}

Neuroendocrine tumors of the rectum are uncommon, however, the incidence rate of carcinoid tumors has increased substantially over the past five decades with the rapid development of screening endoscopy ${ }^{[6]}$. Jetmore $A B$ et al. ${ }^{[7]}$ has predicted that rectal carcinoids may become the most frequent human carcinoid tumor, and a Japanese study illustrated that approximately $90 \%$ of colorectal carcinoids were located in the rectum.

$\operatorname{Rorstad}^{[8]}$ reported that patients with rectal carcinoids had a wide variability in 5-year survival rates which ranged from $62 \%$ to $100 \%$. Small rectal carcinoids are known to have little risk of metastasis, rectal carcinoids without metastasis usually have been considered both associated with a favorable prognosis and a high 5 -year survival rate $(85-99 \%){ }^{[4]}$. Similar data was found in the cohort, the 5- year OS and CSS as well as RFS were $85.2 \%, 93.8 \%$ and $90.9 \%$ respectively. Generally, $86 \%$ of rectal carcinoid tumors size were less than $10 \mathrm{~mm}{ }^{[9]}$. Our study showed that $50 \%(8 / 16)$ patients tumor were $\leq 10 \mathrm{~mm}$. As the disease stage advances, carcinoid tumors develop in the mucosal gland and gradually infiltrate to the deeper layer of the bowel wall and may be in the wake of lymph node or distant metastasis. TNM stage have been believed as predictors in the assessment of survival rate of rectal carcinoids ${ }^{[10]}$, and current treatment modalities are mostly in the light of TNM staging. Ramage et al. ${ }^{[11]}$ reported that for the tumors diameter $\leq 10 \mathrm{~mm}$ which had rarely lymphatics, muscularis propria invasion or lymph nodes metastasis, local excision is appropriate for the tumors in this size. In this study, there were 8 patients with tumor $\leq 10 \mathrm{~mm}$. 6 cases underwent transanal local excision and 2 patients chose ESD. They were well alive except the one died of lung cancer. For the tumors $\geq 20 \mathrm{~mm}$ in size or along with muscularis infringement, the radical resection was the optimal therapy ${ }^{[11]}$. In the study, a patient (patient 4) with a $20 \mathrm{~mm}$-diameter tumor and muscularis infringement underwent transanal local excision depend on his needs. However, he died from recurrent primary tumor one year later. As for rectal carcinoids diameter were $10-20 \mathrm{~mm}$, there was no agreement in the studies concerning the optimal therapy for tumors of this size. Some people supported rectal resection while others held on local excision for selected patients. Ramage et al. ${ }^{[11]}$ suggested local 
excision was reasonable for any rectal carcinoid $\leq$ $20 \mathrm{~mm}$. In the cohort, of 3 male patients with 10-20 $\mathrm{mm}$-diameter lesions and no invading muscular layer and positive lymph nodes. 2 cases chose transanal local excision and 1 patient received Dixon. These 3 patients had not discovered local recurrence or distant metastasis until the time of the last follow- up visit. One of the patients underwent two cycles chemotherapy postoperatively because of lymph nodes involvement (T2N1M0). One of the patients (patient 11) with an inadequate resection underwent postoperative radiation therapy. Usually, rectal carcinoids are considered as well -differentiated tumors, adjuvant therapies should not be recommended.Additionally, active double cancer and the nuclear proliferation marker were considered to be important factors of affecting the rectal carcinoids survival rate. There are studies ${ }^{[12,13]}$ suggested that patients with colorectal carcinoid tumors had an increased risk of synchronous primary cancer. The rate of a carcinoid tumor with a second primary malignancy ranges from 12 to $46 \%$. Tichansky et al. ${ }^{[12]}$ also found that patients with colorectal carcinoids had a high susceptibility of second primary cancer in other sites, such as small bowel, esophagus, stomach, lung and bronchus simultaneously. When the second tumor is a more malignant lesion, the prognosis may be correlated closer with the noncarcinoid cancer ${ }^{[13]}$. In our study, we had a patient with active double cancer died from lung cancer after ESD of rectal carcinoid. The monoclonal antibody Ki-67 had been believed to be the nuclear proliferation marker, providing a measurement for the growth fraction in several different tumors ${ }^{[14]}$. Hotta $\mathrm{K}$ et al. ${ }^{[15]}$ reported that the $\mathrm{Ki}-67$ ratio was an effective histological parameter to predict metastatic behavior of rectal carcinoid tumors. In our study, Ki-67 of all lesions were below 4\%, which indicated a low cellular proliferative activity in rectal carcinoids. The outcome was in accordance with the report of Shimizu $\mathrm{T}^{[16]}$.

In conclusion, rectal carcinoids have diverse biological characteristics and a favorable prognosis. An adequate resection play key role in management of rectal carcinoid tumor, the extent of the surgical resection depend on its size, its anticipated stage and the specific patient needs. In addition, the small sample size and a single institution are notable limit in this study, it is desirable to build multi-institution cooperation to explore the appropriate therapy modality for different patients with rectal carcinoids

Tab. 1. Patient characteristics

\begin{tabular}{|c|c|c|c|c|c|c|c|c|c|c|}
\hline $\begin{array}{l}\text { Pat } \\
\text { no. }\end{array}$ & Sex & $\begin{array}{l}\text { Age } \\
\text { (y) }\end{array}$ & $\mathrm{D}(\mathrm{mm})$ & DTI & $\mathrm{Ki}-67(\%)$ & LNM & DAV & $\mathrm{OM}$ & AT & Staging \\
\hline 1 & $\mathrm{M}$ & 48 & 21 & Muscularis & 3.5 & yes & 2 & Dixon & Chemo & $\mathrm{T} 2 \mathrm{~N} 1 \mathrm{M} 0$ \\
\hline 2 & $\mathrm{M}$ & 42 & 7 & Submucosa & 2.0 & no & 7 & LE & no & T1aN0M0 \\
\hline 3 & $\mathrm{M}$ & 40 & 15 & Mucosa & 2.5 & no & 7 & LE & no & T1b N0M0 \\
\hline 4 & M & 29 & 21 & Muscularis & 1.5 & no & 8 & LE & no & T2 N0M0 \\
\hline 5 & $\mathrm{M}$ & 57 & 22 & Muscularis & 3.0 & no & 8 & APR & no & T2 N0M0 \\
\hline 6 & $\mathrm{M}$ & 37 & 11 & Submucosa & 2.0 & no & 5 & LE & no & T1b N0M0 \\
\hline 7 & $\mathrm{~F}$ & 42 & 5 & Submucosa & 1.0 & no & 6 & LE & no & T1 a N0M0 \\
\hline 8 & $\mathrm{~F}$ & 42 & 23 & Submucosa & 1.0 & no & 5 & Dixon & no & T1b N0M0 \\
\hline 9 & $\mathrm{~F}$ & 65 & 5 & Submucosa & 1.5 & no & 3 & LE & no & T1 a N0M0 \\
\hline 10 & $\mathrm{M}$ & 58 & 21 & Submucosa & 0.3 & no & 10 & APR & no & T2 N0M0 \\
\hline 11 & $\mathrm{~F}$ & 41 & 8 & Submucosa & 2.0 & no & 4 & LE & RT & T1 a N0M0 \\
\hline 12 & $\mathrm{~F}$ & 47 & 8 & Submucosa & 1.0 & no & 5 & LE & no & T1a N0M0 \\
\hline 13 & $\mathrm{~F}$ & 46 & 6 & Muscularis & 2.6 & no & 6 & LE & no & T2 N0M0 \\
\hline 14 & $\mathrm{M}$ & 50 & 16 & Submucosa & 1.2 & no & 7 & Dixon & no & T1b N0M0 \\
\hline 15 & $\mathrm{M}$ & 61 & 5 & Submucosa & 0.4 & no & 6 & ESD & no & T1 a N0M0 \\
\hline 16 & $\mathrm{M}$ & 78 & 3 & Submucosa & 1.7 & no & 5 & ESD & no & T1a N0M0 \\
\hline
\end{tabular}




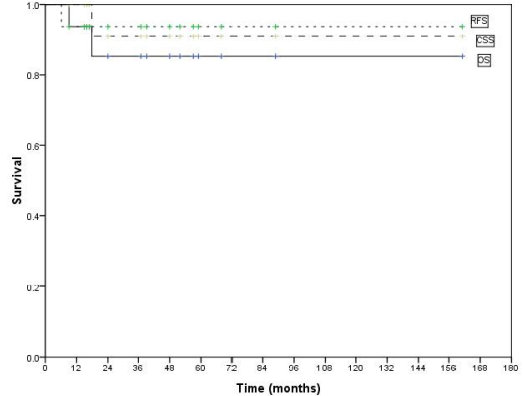

Fig.1 Abbreviation: Overall survival (Solid line), Recurrence-free survival (dotted line) and Cancerspecific survival (dashed line) of 16 patients.

\section{Corresponding Author:}

\section{Dr. Ge}

Department of radiation oncology

Henan cancer hospital, the Affiliated Cancer Hospital of Zhengzhou University, Zhengzhou 450001Henan Province, China. E-mail: gehong66@gmail.com

\section{References}

1. Teleky B, Herbst F, Langle F, Neuhold N, Niederle B. The prognosis of rectal carcinoid tumours. Int J Colorectal Dis 1992; 7:11-14.

2. Klöppel G, Perren A, Heitz PU. The gastroenteropancreatic neuroendocrine cell system and its tumors: the WHO classification. Ann N Y Acad Sci 2004; 1014: 13-27.

3. Konishi T, Watanabe T, Kishimoto J, Kotake K, Muto T, Nagawa H. Prognosis and risk factors of metastasis in colorectal carcinoids: results of a nationwide registry over 15 years. Gut 2007; 56: 863-868.

4. Soga J. Early-stage carcinoids of the gastrointestinal tract: an analysis of 1914 reported cases. Cancer 2005; 103:1587-1595.

5. Edge SB, Compton CC. The American Joint Committee on Cancer: the 7th edition of the AJCC cancer staging manual and the future of TNM. Ann Surg Oncol 2010; 17:1471-1474.

6. Modlin IM, Oberg K, Chung DC, Jensen RT, de Herder WW, Thakker RV, et al. Gastroenteropancreatic neuroendocrine tumours. Lancet Oncol 2008; 9: 61-72.

7. Jetmore AB, Ray JE, Gathright JB Jr, McMullen
KM, Hicks TC, Timmcke AE. Rectal carcinoids: the most frequent carcinoid tumor. Dis Colon Rectum 1992; 35:717-725.

8. Rorstad O. Prognostic indicators for carcinoid neuroendocrine tumors of the gastrointestinal tract. J Surg Oncol 2005; 89:151-160.

9. Kobayashi K, Katsumata T, Yoshizawa S, Sada M, Igarashi M, Saigenji K, et al. Indications of endoscopic polypectomy for rectal carcinoid tumors and clinical usefulness of endoscopic ultrasonography. Dis Colon Rectum 2005; 48: 285-291.

10. Yoon SN, Yu CS, Shin US, Kim CW, Lim SB, Kim JC. Clinicopathological characteristics of rectal carcinoids. Int J Colorectal Dis 2010; 25:1087-1092.

11. Ramage JK, Goretzki PE, Manfredi R, Komminoth P, Ferone D, Hyrdel R, et al. Consensus guidelines for the management of patients with digestive neuroendocrine tumours: well-differentiated colon and rectum tumour/carcinoma. Neuroendocrinology 2008; 87: 31-39.

12. Tichansky DS, Cagir B, Borrazzo E, Topham A, Palazzo J, Weaver EJ, et al. Risk of second cancers in patients with colorectal carcinoids. Dis Colon Rectum 2002; 45: 91-97.

13. Li AF, Hsu CY, Li A, Tai LC, Liang WY, Li WY, et al. A 35-year retrospective study of carcinoid tumors in Taiwan: differences in distribution with a high probability of associated second primary malignancies. Cancer 2008; 112: 274-283.

14. Bozlu M, Orhan D, Baltaci S, Yaman O, Elhan $\mathrm{AH}$, Tulunay $\mathrm{O}$, et al. The prognostic value of proliferating cell nuclear antigen, Ki-67 and nucleolar organizer region in transitional cell carcinoma of the bladder. Int Urol Nephrol 2002; 33: 59-66.

15. Hotta K, Shimoda T, Nakanishi Y, Saito D. Usefulness of Ki-67 for predicting the metastatic potential of rectal carcinoids. Pathol Int 2006; 56: 591-596.

16. Shimizu T, Tanaka S, Haruma K, Kitadai Y, Yoshihara M, Sumii K, et al. Growth characteristics of rectal carcinoid tumors. Oncology 2000; 59: 229. 